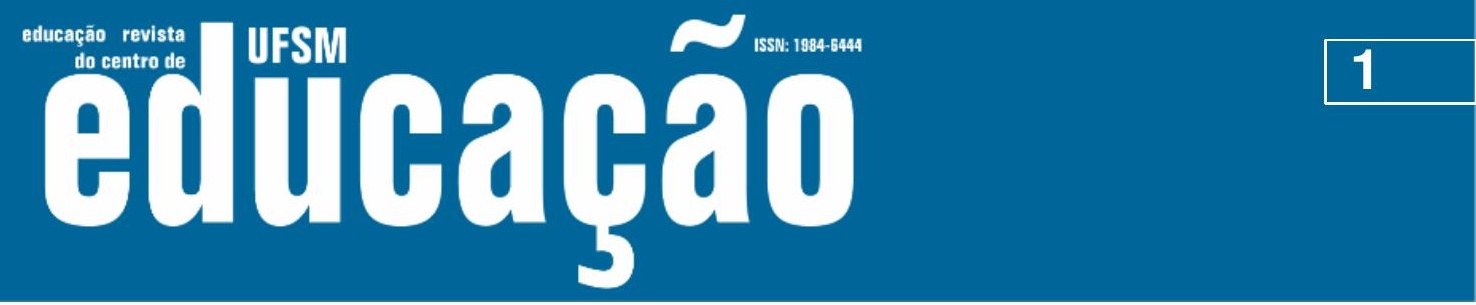

ISSN: 1984-6444 | http://dx.doi.org/10.5902/1984644434206

\title{
Ensino de Ciências para todos: uma experiência com um estudante com deficiência intelectual
}

\author{
Science education for all: An experience with a student presenting \\ intellectual disabilities
}

\author{
Ronaldo Santos Santana \\ Universidade de São Paulo \\ Cássia Geciauskas Sofiato \\ Universidade de São Paulo
}

\section{RESUMO}

Atualmente, os pesquisadores no âmbito da educação em ciências têm explorado campos de investigações que, durante muito tempo, foram negligenciados em função da ausência de pesquisas. Exemplos disso são os estudos, ainda escassos, envolvendo o ensino de ciências para estudantes com deficiência intelectual. Por isso, o objetivo deste artigo é apresentar os resultados da implementação de uma prática que envolve a utilização de diferentes estratégias pedagógicas, implementadas por um professor de ciências dos anos finais do ensino fundamental para ensinar um estudante com deficiência intelectual. O referencial teórico que embasou a elaboração das estratégias utilizadas foi o pluralismo metodológico no ensino de ciências e o ensino por investigação. Para atingir os objetivos, foi realizada uma pesquisa qualitativa com base nos instrumentos de avaliação do professor de ciências e em documentos relativos ao estudante, arquivados na escola. Os dados foram tratados por meio da análise textual discursiva. A análise dos dados evidenciou que é possível e necessário o uso de diferentes estratégias para ensinar ciências a estudantes com deficiência intelectual, como a utilização de recursos didáticos lúdicos, multissensoriais, envolvendo diferentes linguagens e atividades investigativas. Foram destacados também alguns desafios, a saber: o pouco tempo remunerado disponível para o planejamento das atividades pedagógicas e a grande quantidade de alunos em sala de aula. As discussões apresentadas podem auxiliar professores e pesquisadores no âmbito do ensino de ciências a compreender como ensinar a todos. Palavras-chave: Educação em ciências; Educação especial; Estratégias pedagógicas.

\section{ABSTRACT}

Currently, researchers in science education are exploring fields of investigation that have long been neglected, due to lack of research. These include the still-scarce studies involving science education for students with intellectual disabilities. In this context, the purpose of this article is to present the results of the implementation of a 


\section{Usism Eulloab̧a}

ISSN: 1984-6444 | http://dx.doi.org/10.5902/1984644434206

pedagogical practice involving the use of different pedagogical strategies implemented by a science teacher in the final years of elementary education to teach a student with intellectual disabilities. The theoretical frameworks that supported the elaboration of the applied strategies were methodological pluralism in science teaching and research teaching. In order to achieve the objectives of the study, a qualitative research was carried out, based on the evaluation instruments of the science teacher and on documents related to the student, filed at the school. Data were analyzed through a discursive textual analysis. The analyzed data indicate that it is possible, and necessary, to use different strategies to teach science to students with intellectual disabilities, such as the use of playful, multi-sensory didactic resources involving different languages and research activities. Some challenges were also highlighted, namely the limited paid time available for the planning of the pedagogical activities and the large number of students in the classroom. The discussions presented herein can aid teachers and researchers in the field of science teaching to understand how to teach one and all.

Keywords: Science education; Special education; Pedagogical strategies.

\section{Introdução}

A educação formal tem como uma de suas premissas proporcionar a todos os estudantes o seu desenvolvimento integral, por meio de intervenções didáticas planejadas e intencionais, além de formar os estudantes para terem a capacidade de se posicionar criticamente e continuar explorando o mundo (aprendendo) de maneira autônoma. Entretanto, para que uma educação de "qualidade" seja de fato estendida a todos, o professor precisa, frequentemente, utilizar estratégias diferenciadas.

A polissemia da expressão "qualidade na educação" exige que façamos ponderações a esse respeito. De acordo com Oliveira e Araújo (2005), até para os especialistas é difícil chegar a uma concepção do que seria qualidade na educação. No decorrer da história, os autores afirmam que:

[...] na educação brasileira, três significados distintos de qualidade foram construídos e circularam simbólica e concretamente na sociedade: um primeiro, condicionado pela oferta limitada de oportunidades de escolarização; um segundo, relacionado à ideia de fluxo, definido como número de alunos que progridem ou não dentro de determinado sistema de ensino; e, finalmente, a ideia de qualidade associada à aferição de desempenho mediante testes em larga escala (OLIVEIRA; ARAUJO, 2005, p. 8).

Dessa forma, o primeiro sentido de qualidade na educação está relacionado ao acesso da educação a todas as pessoas, enquanto que o segundo refere-se à permanência desses sujeitos no processo de escolarização e à evolução desses nos 


\section{W Lism olluarao

ISSN: 1984-6444 | http://dx.doi.org/10.5902/1984644434206

sistemas de ensino. O terceiro relaciona-se ao sucesso que os estudantes têm em avaliações de larga escala, atribuindo a educação de qualidade àquela que permite o progresso ascendente dos estudantes em tais testes. Contudo, é válido ressaltar que, ainda hoje, essas três concepções de qualidade podem existir em diversos contextos educacionais e são passíveis de serem problematizadas.

Para contribuir com o debate sobre a qualidade na educação, destacaremos também os posicionamentos de Gadotti (2010). Este autor defende que a temática da qualidade na educação é dinâmica e tem sido discutida por meio de diversas perspectivas que envolvem fatores intra e extraescolares, além de questões subjetivas que podem fazer parte desse processo.

Logo, para avançar na questão da qualidade na educação, é importante melhorar as condições para a atuação do docente por meio de ações dentro da própria escola e não perder de vista questões de ordens mais gerais, tais como: transporte; saúde; alimentação; esporte; e lazer da população (GADOTTI, 2010). Assim sendo, o autor defende que a qualidade na educação é um tema histórico e complexo, não bastando melhorar apenas um aspecto, mas incitando a pensar em diversas questões para que ela seja conquistada.

Dentro do discurso sobre a qualidade do ensino e sobre a oferta de uma educação para todos, é importante também proporcionar uma educação de qualidade para estudantes que são o público-alvo da educação especial, a saber, pessoas com deficiência, transtornos globais do desenvolvimento, altas habilidades/superdotação.

Para também ofertar uma educação integral a estudantes com essas singularidades, é importante que o professor tenha uma prática inclusiva. Neste estudo, com base em Bueno (2008), entendemos a inclusão como uma "proposição política em ação" e, de acordo com Rodrigues (2006), o conceito de inclusão no âmbito da educação tem algumas especificidades:

\footnotetext{
O conceito de Inclusão no âmbito específico da Educação, implica, antes de mais, rejeitar, por princípio, a exclusão (presencial ou académica) de qualquer aluno da comunidade escolar. Para isso, a escola que pretende seguir uma política de Educação Inclusiva (EI) desenvolve políticas, culturas e práticas que valorizam o contributo ativo de cada aluno para a construção de um conhecimento construído e partilhado e desta forma atingir a qualidade académica e sócio cultural sem discriminação.
} 


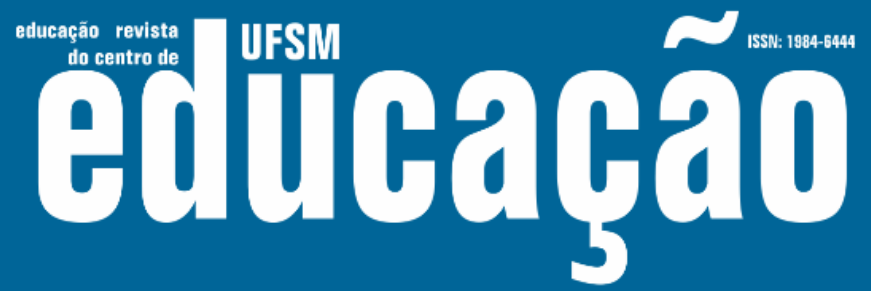

ISSN: 1984-6444 | http://dx.doi.org/10.5902/1984644434206

Entendendo como natural a diversidade entre os seres humanos, a educação escolar deve ter como princípio atender a todos, mesmo que seja preciso realizar adaptações estruturais e didáticas (SANTOS, 2012). É válido destacar que nem em uma sala de aula sem estudantes do público-alvo da educação especial há homogeneidade, por isso, estratégias didáticas diferenciadas com a finalidade de propiciar uma educação integral e de qualidade para o máximo de estudantes são essenciais.

Entretanto, a implementação de uma educação inclusiva, algumas vezes, tem se materializado em garantir vagas em classes comuns apenas a alunos com alguma necessidade educacional especial, e essa distorção da inclusão tem sido um grande desafio para a concretização da tão almejada educação para todos (PRIETO, 2006).

Mantoan (2006) declara que essa distorcida noção de igualdade de oportunidades é desafiadora, pois garante o acesso, mas não a permanência e o prosseguimento da educação na escola básica. Segundo a autora, esse fato só corrobora a importância de se repensar e interromper uma cultura educacional elitista nas escolas brasileiras, reconhecendo a igualdade na educação como um ponto de partida e as diversidades na aprendizagem como processo e ponto de chegada. Por isso, é preciso garantir a oferta de vaga, a permanência e um padrão mínimo de qualidade na educação de todos os estudantes.

Porém, Duarte (2007) afirma que a realidade evidencia que a qualidade da educação escolar ainda é algo distante em nosso país, especialmente para as classes mais desamparadas da nossa sociedade, como, por exemplo, os estudantes com deficiência. Por isso, ressalta-se que devem ser pensadas ações efetivas para que a inclusão de pessoas com deficiência não seja caracterizada apenas como garantia de matrícula, mas pelo oferecimento de condições para a permanência dos estudantes no processo de escolarização (VILELA-RIBEIRO; BENITE, 2013). Prieto (2006) aponta que é um equívoco imaginar que existem estudantes que vão à escola apenas para se socializar com os demais colegas enquanto outros vão para aprender. A autora afirma que a "escola é espaço de aprendizagem para todos!" (p. 60).

Discutir a qualidade na educação requer também que se pense em um currículo razoável às condições acadêmicas e contextuais dos estudantes para que, de fato, 


\section{Autuaŗão}

ISSN: 1984-6444 | http://dx.doi.org/10.5902/1984644434206 todos tenham condições de aprender. Contudo, ainda não é uma realidade na prática escolar a construção de um programa curricular flexível, visando a atender à diversidade em sala de aula e ensinar a todos os estudantes, sejam eles pertencentes ao público-alvo da educação especial ou não (COSTA et al., 2015). Alunos com deficiência intelectual ${ }^{1}$, que compõem o público-alvo da Educação Especial, demandam uma atenção em relação ao currículo para que sua aprendizagem seja significativa e efetiva.

Por mais que não seja possível a reversão do quadro de deficiência intelectual de uma pessoa, em função de envolver o desenvolvimento neurológico, é possível a aprendizagem de conhecimentos igualmente aos demais alunos sem deficiência (SANTOS, 2012). Dessa forma, se o estudante com deficiência intelectual for estimulado por meio de ações pedagógicas que usam recursos apropriados e com objetivos definidos, ele pode apresentar um bom desempenho acadêmico em diversos casos (MIRANDA; PINHEIRO, 2016; SILVA; SHIMAZAKI; MENEGASSI, 2017).

Um exemplo de disciplina escolar na qual o aluno com deficiência intelectual pode apresentar avanços em aspectos de sua aprendizagem é a disciplina de ciências (COSTA et al., 2015; MIRANDA; PINHEIRO, 2016). Para isso, é recomendada a realização de uma educação em ciências e tecnologia que utilize diferentes estratégias didáticas para o ensino de estudantes com deficiência intelectual (COSTA et al., 2015).

Entretanto, na literatura nacional da área, ainda é muito pequeno o número de pesquisas publicadas envolvendo o ensino de ciências para estudantes com deficiência intelectual. Por exemplo, Costa et al. (2015) publicaram um artigo sobre aspectos do ensino de ciências para uma turma de estudantes do $5^{\circ}$ ano do ensino

\footnotetext{
${ }^{1} \mathrm{O}$ conceito de deficiência intelectual utilizado nesta pesquisa é aquele empregado pela American Association on Intellectual and Developmental Disabilities (AAIDD), que define a deficiência intelectual como uma deficiência caracterizada por consideráveis limitações no que se refere ao funcionamento intelectual e ao comportamento adaptativo, que abrange muitas habilidades sociais e práticas cotidianas, sendo expressa antes dos 18 anos de idade (AAIDD, 2018). A AAIDD compreende o funcionamento intelectual como capacidades mentais gerais que se relacionam à aprendizagem, ao raciocínio, à resolução de problemas, entre outros. Enquanto que o comportamento adaptativo se refere a um grupo de habilidades conceituais, sociais e práticas, que são comumente aprendidas e utilizadas pelos indivíduos no seu dia-dia.
} 


\section{Autuarão}

ISSN: 1984-6444 | http://dx.doi.org/10.5902/1984644434206

fundamental de uma escola particular e, dentre eles, estava uma estudante com deficiência intelectual. Assim, os autores analisaram a importância do professor tutor no ensino e na aprendizagem dessa estudante. Miranda e Pinheiro (2016), por sua vez, realizaram uma pesquisa que discutiu aspectos da ressignificação na educação em ciências e matemática de estudantes com deficiência intelectual no âmbito da implementação de um projeto contextualizado com alunos do $2^{\circ}$ ano do ensino fundamental.

A ausência de pesquisas pode ser um indicador de que essa área tem sido negligenciada na academia e isso pode impactar na formação para o trabalho com essas crianças, bem como no ensino. Devido a isso, o objetivo deste trabalho é apresentar os resultados da implementação de uma prática pedagógica que envolveu a utilização de diferentes estratégias realizadas por um professor de ciências, nos anos finais do ensino fundamental, com um estudante diagnosticado com deficiência intelectual e a turma em que ele está inserido. Este trabalho assume um caráter inovador, uma vez que produções relacionadas ao tema são escassas e, ao mesmo tempo, necessárias para a escola hodierna.

\section{Metodologia}

Considerando as contribuições de Bogdan e Biklen (1994) para as investigações em educação, a presente pesquisa caracteriza-se como qualitativa. Assim, foram considerados os cinco critérios dos autores para relacioná-la a esse grupo de pesquisa: (I) a fonte direta dos dados é o ambiente natural e o pesquisador apresenta um papel fundamental no processo; (II) a investigação tem um caráter descritivo; (III) o processo é mais importante que os resultados ou os produtos; (IV) os pesquisadores analisam os seus dados de maneira indutiva, ou seja, "não recolhem dados ou provas com o objetivo de confirmar ou infirmar hipóteses construídas previamente; ao invés disso, as abstrações são construídas à medida que os dados particulares que foram recolhidos se vão agrupando (BOGDAN; BIKLEN, 1994, p. 50)"; (V) por fim, em pesquisas qualitativas, é atribuída grande importância aos significados e sentidos que os sujeitos dão aos fenômenos. 


\section{Autดaคูão}

ISSN: 1984-6444 | http://dx.doi.org/10.5902/1984644434206

Este estudo é resultante de uma prática pedagógica desenvolvida por um professor de ciências, contendo a descrição de algumas estratégias realizadas, atreladas a uma análise crítica. $\mathrm{O}$ trabalho foi desenvolvido em uma escola pública na cidade de São Paulo, que atende alunos dos anos iniciais e finais do ensino fundamental.

Os dados que serviram de base para as reflexões foram extraídos de: (1) instrumentos de avaliação do professor de ciências de fevereiro a agosto de 2018, no período equivalente ao primeiro, segundo e terceiro bimestre da escola; e (2) documentos relativos ao estudante, arquivados na escola.

Os instrumentos de avaliação do professor de ciências são o planejamento anual e bimestral, as suas anotações e os seus registros diários, a pasta de atividades de ciências preparadas pelo professor e alguns registros em vídeo produzidos em uma de suas aulas. Tais instrumentos são utilizados pelo professor rotineiramente em sua prática e não foram criados somente para a realização do presente estudo.

Os sujeitos participantes deste estudo foram os estudantes de uma turma do $7^{\circ}$ ano do ensino fundamental, sendo que o olhar estava especificamente voltado a um estudante que apresenta o diagnóstico de deficiência intelectual. No prontuário do estudante, há um laudo de um profissional da área médica atestando que o estudante tem deficiência intelectual e necessita de um professor auxiliar de sala. É importante salientar que o professor de ciências não utilizou tal documento para guiar as práticas pedagógicas a serem realizadas com o aluno em questão. O professor tomou ciência e realizou a leitura dele, pois fazia parte dos documentos que o estudante tinha em seu prontuário.

Esse estudante está matriculado na referida escola desde o primeiro ano do ensino fundamental e acompanha uma mesma turma desde o terceiro ano. Nessa turma, há 33 estudantes. O aluno com deficiência intelectual tem 14 anos. As menções ao aluno serão realizadas por meio de um pseudônimo, Pedro, para garantir o sigilo de sua identidade.

As intervenções pedagógicas com a finalidade de ensinar ciências para Pedro foram realizadas de maneira pontual e continuada, visando a atender às singularidades e potencialidades do aluno para que, dessa forma, fosse realizada de 


\section{OF HW elturarao

ISSN: 1984-6444 | http://dx.doi.org/10.5902/1984644434206

fato a educação em ciências e essa se estendesse para todos os estudantes, indistintamente. Esse era o objetivo do professor: ensinar ciências para todos os estudantes e tentar ao máximo atender à diversidade existente em sala de aula. As aulas planejadas consideravam as condições dos estudantes e pretendia-se realizar atividades que envolviam o trabalho com conhecimentos científicos, utilizando diferentes estratégias pedagógicas.

Assim, visava-se contemplar a proposta do pluralismo metodológico de Laburú, Arruda e Nardi (2003). De maneira geral, em função de o ensino/aprendizagem de ciências modificar-se de acordo com o tempo, além de ser complexo, envolver diversos saberes e não ser trivial, é recomendado que o professor utilize diversas metodologias para o ensino, sendo questionáveis práticas pedagógicas que privilegiem um estilo didático em detrimento dos demais, abrangendo assim as necessidades de apenas um grupo específico de estudantes (LABURÚ; ARRRUDA; NARDI, 2003).

Dessa forma, para tentar atender a todos, algumas das atividades implementadas com o Pedro eram diferentes daquelas dos demais alunos do $7^{\circ}$ ano. Entretanto, na medida do possível, o professor de ciências tinha o cuidado de planejar as atividades de Pedro com o mesmo conteúdo que a turma estava estudando, conforme observado no quadro a seguir:

Quadro 1 - Temas de Ciências desenvolvidos com os estudantes durante o período do estudo

\section{Conteúdos do currículo da turma}

$\checkmark$ Constituição dos materiais por substâncias.

$\checkmark \quad$ Misturas homogêneas e heterogêneas.

$\checkmark$ Tabela Periódica.

$\checkmark$ Movimento.

$\checkmark$ Astronomia

$\checkmark$ Locomoção e sistemas locomotores em diversos seres vivos.

\section{Conteúdos desenvolvidos com Pedro}

Constituição dos materiais por substâncias.

$\checkmark$ Misturas homogêneas e heterogêneas.

$\checkmark$ Tabela Periódica.

$\checkmark$ Fenômenos Físicos.

$\checkmark$ Astronomia

$\checkmark$ Locomoção e sistemas locomotores em diversos seres vivos.

Fonte: Plano de ensino do professor de Ciências (2018).

Os conteúdos apresentados no quadro anterior foram desenvolvidos com a turma por meio da utilização de diversas estratégias didáticas, que acabaram contemplando às necessidades de Pedro e dos demais estudantes. As aulas de ciências foram ministradas quatro vezes por semana. $O$ quadro a seguir, demonstra as principais estratégias pedagógicas utilizadas pelo professor de ciências para 


\section{N Futorbुa}

ISSN: 1984-6444 | http://dx.doi.org/10.5902/1984644434206 abordar os conteúdos indicados anteriormente, os seus objetivos e os materiais utilizados para implementá-los:

Quadro 2 - Estratégias utilizadas com os alunos nos três bimestres

\begin{tabular}{|c|c|c|}
\hline Estratégias & Atividades e objetivos & Materiais \\
\hline \multirow{5}{*}{$\begin{array}{l}\text { Materiais } \\
\text { lúdicos e } \\
\text { múltiplas } \\
\text { linguagens }\end{array}$} & $\begin{array}{l}\text { Tabela periódica ilustrada: desenvolver conhecimentos } \\
\text { químicos relacionados à tabela periódica dos elementos, } \\
\text { com ilustrações de locais do cotidiano em que são } \\
\text { encontrados tais elementos químicos. }\end{array}$ & $\begin{array}{l}\text { Impressão colorida de } \\
\text { ilustrações de materiais } \\
\text { que possuem alguns } \\
\text { elementos da tabela } \\
\text { periódica. }\end{array}$ \\
\hline & $\begin{array}{l}\text { Atividade envolvendo diferentes representações para } \\
\text { uma mesma molécula: compreender, por meio de } \\
\text { esquemas e desenhos, que um mesmo elemento } \\
\text { químico pode formar diferentes moléculas. }\end{array}$ & $\begin{array}{l}\text { Atividade impressa em } \\
\text { folha de tamanho A4, } \\
\text { colorido. Lápis e papel. }\end{array}$ \\
\hline & $\begin{array}{l}\text { Pintura de desenhos de ciências: pintar desenhos que } \\
\text { ilustram diferentes locais onde podem ser encontrados } \\
\text { alguns elementos químicos. }\end{array}$ & $\begin{array}{l}\text { Atividade impressa em } \\
\text { folha de tamanho A4, } \\
\text { preto e branco e lápis. }\end{array}$ \\
\hline & $\begin{array}{l}\text { Caça-palavras de conhecimentos químicos: realizar uma } \\
\text { atividade do tipo caça-palavras, em que o objetivo é } \\
\text { encontrar palavras que estão relacionadas ao } \\
\text { conhecimento químico. }\end{array}$ & $\begin{array}{l}\text { Atividade impressa em } \\
\text { folha de tamanho A4, } \\
\text { lápis e papel. }\end{array}$ \\
\hline & $\begin{array}{l}\text { Avaliação de conhecimentos científicos ilustrada: avaliar } \\
\text { os conhecimentos científicos de astronomia, utilizando } \\
\text { figuras, imagens, histórias em quadrinho, gráficos, } \\
\text { tabelas, desenhos e esquemas. }\end{array}$ & $\begin{array}{l}\text { Atividade impressa em } \\
\text { folha de tamanho A4, } \\
\text { colorido e lápis. }\end{array}$ \\
\hline \multirow{2}{*}{$\begin{array}{l}\text { Ensino de } \\
\text { Ciências por } \\
\text { investigação }\end{array}$} & $\begin{array}{l}\text { Atividade investigativa sobre os flamingos em uma } \\
\text { região de mangue: investigar aspectos da densidade } \\
\text { populacional de flamingos que vivem no mangue, em } \\
\text { uma atividade investigativa envolvendo lápis, papel e } \\
\text { discussão. }\end{array}$ & $\begin{array}{l}\text { Atividade impressa em } \\
\text { folha de tamanho A4, } \\
\text { colorido e lápis. Os } \\
\text { estudantes foram } \\
\text { dispostos em grupos. }\end{array}$ \\
\hline & $\begin{array}{l}\text { Pesquisando sobre o sexo biológico dos flamingos: } \\
\text { segunda atividade investigativa que surgiu a partir da } \\
\text { realizada anteriormente, com o objetivo de investigar } \\
\text { estratégias para distinguir os flamingos pelo seu sexo } \\
\text { biológico. }\end{array}$ & $\begin{array}{l}\text { Computador, lápis e } \\
\text { papel. A atividade foi } \\
\text { realizada no laboratório } \\
\text { de informática. }\end{array}$ \\
\hline
\end{tabular}

Fonte: Planejamento do professor (2018).

A partir do delineamento das atividades, objetivos, estratégias e materiais utilizados, apresentaremos, a seguir, a prática desenvolvida e as análises realizadas à luz da Análise Textual Discursiva (ATD), com base nas contribuições de Moraes e Galiazzi (2016). Os autores afirmam que a ATD pode ser compreendida como uma metodologia de análise de dados qualitativos que consiste em um grupo de diversos métodos que têm como seu principal objeto a análise de textos, incluindo, de um lado, a análise do discurso e, de outro, a análise de conteúdo. A ATD tem como objetivo elaborar outras compreensões a respeito dos fenômenos e discursos (MORAES; 


\section{Wusm Futlagha}

ISSN: 1984-6444 | http://dx.doi.org/10.5902/1984644434206

GALIAZZI, 2016). No processo analítico, foram considerados principalmente os três primeiros focos da ATD, a saber: (I) a desmontagem dos textos; (II) o estabelecimento de relações; (III) e a captação do novo emergente.

\section{Resultados e Discussão}

O relatório da professora de apoio e acompanhamento à inclusão de Pedro atesta que o estudante é alfabetizado e necessita de intervenções pedagógicas adequadas. Esse documento serviu como base para as primeiras intervenções pedagógicas do professor de ciências no início do ano. O trabalho, realizado no período de fevereiro a agosto de 2018, evidenciou algumas possibilidades relativas ao ensino de ciências para o Pedro e os demais estudantes. Além disso, foram também destacados alguns desafios enfrentados pelo professor em função das dificuldades de ensinar ciências para um estudante com a condição de Pedro. $O$ quadro a seguir (quadro 3) sintetiza as principais possibilidades e desafios percebidos por meio da prática analisada na pesquisa.

Quadro 3 - Possibilidades apresentadas e desafios enfrentados ao ensinar ciências a Pedro.

\begin{tabular}{|l|l|}
\hline \multicolumn{1}{|c|}{ Possibilidades } & \multicolumn{1}{|c|}{ Desafios } \\
\hline - $\begin{array}{l}\text { Trabalhar com o estudante com deficiência intelectual os } \\
\text { mesmos temas que foram desenvolvidos com os demais alunos. }\end{array}$ & $\begin{array}{l}\text { Pouco tempo disponível } \\
\text { para o planejamento. } \\
\text { Dificuldade em } \\
\text { - Trabalhar com recursos didáticos lúdicos, visando à } \\
\text { contextualização do ensino com aspectos do cotidiano das } \\
\text { pessoas. }\end{array}$ \\
$\begin{array}{l}\text { Desenvolver com o estudante atividades diferenciadas, com com Pedro } \\
\text { vistas a atender as suas singularidades. } \\
\text { Implementar atividades investigativas incluindo o estudante com } \\
\text { deficiência intelectual. }\end{array}$ & $\begin{array}{l}\text { propostos na matriz } \\
\text { curricular para o seu } \\
\text { ano escolar. } \\
\text { Realização de uma avaliação de maneira contínua e também } \\
\text { pontual, envolvendo aspectos conceituais, procedimentais e } \\
\text { atitudinais. }\end{array}$ \\
$\begin{array}{l}\text { Auxilio de um estagiário para ajudar o professor no trabalho com trabalhar } \\
\text { estudantes com deficiência intelectual. }\end{array}$ & $\begin{array}{l}\text { conhecimentos da física } \\
\text { com o estudante com } \\
\text { deficiência intelectual. } \\
\text { Grande quantidade de } \\
\text { alunos em sala de aula. }\end{array}$ \\
\hline
\end{tabular}
Fonte: Registros do professor (2018).

A primeira possibilidade evidenciada foi relatada no quadro 1 , que seria trabalhar com o estudante com deficiência intelectual os mesmos temas que foram desenvolvidos com os demais alunos, inclusive, algumas vezes, utilizando-se a mesma estratégia usada com os demais. Para alcançar as potencialidades de Pedro, no entanto, o professor precisou desenvolver com ele atividades com estratégias 


\section{Ej|lिa \\ 1SSN: $1984-6444$}

ISSN: 1984-6444 | http://dx.doi.org/10.5902/1984644434206

diferenciadas e lúdicas, como pode ser observado nas figuras a seguir, que apresentam uma atividade desenvolvida com Pedro no momento em que o professor estava trabalhando aspectos da tabela periódica dos elementos:

Figura 1 - Atividades desenvolvidas com os estudantes envolvendo conhecimentos químicos. Figura (a), tabela periódica lúdica utilizada com todos os estudantes; figura (b) e (c), atividade sobre elementos químicos, utilizada somente com Pedro.

a)

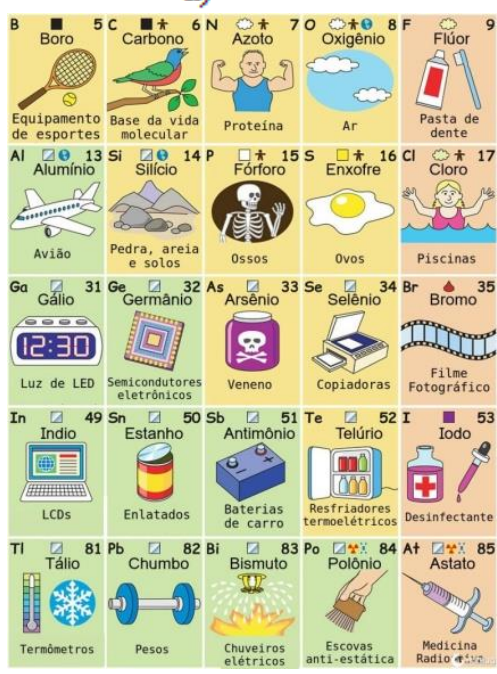

b)

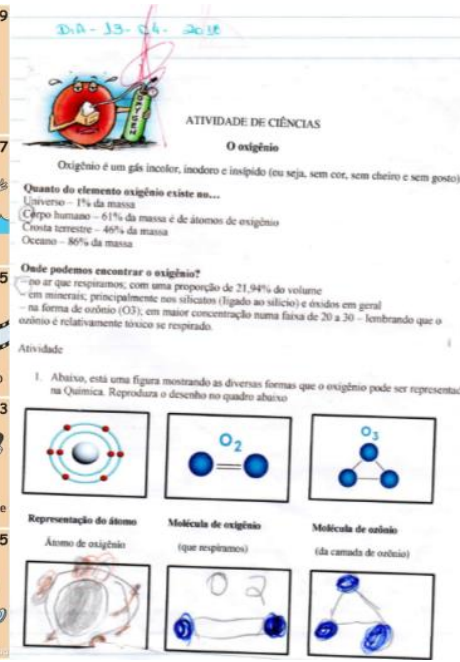

c)

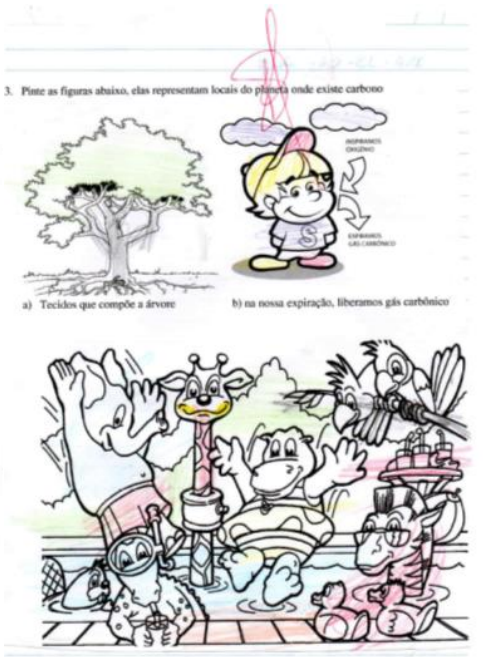

Fonte: figura (a) - Isto é Superinteressante. Disponível em $<h t t p: / / w w w . i s t o e s u p e r i n t e r e s s a n t e . c o m / ? p=25608>$. Acesso em: 28 jul. 2018; figura (b) e (c) Instrumentos de avaliação do professor.

A figura (a), retirada da internet, apresenta lugares onde podem ser encontrados alguns elementos da tabela periódica no cotidiano das pessoas. O trabalho com essa figura destaca mais uma possibilidade, que seria a de trabalhar com recursos didáticos lúdicos visando à contextualização do ensino com aspectos do cotidiano das pessoas. A mediação do professor para a aprendizagem de conceitos em ciências é fundamental para que os estudantes consigam realizar as atividades. Além disso, a construção conceitual de forma lúdica pode ser uma opção nas aulas de ciências (CORRÊA, 2016).

É válido ressaltar que essa figura foi disponibilizada para todos os estudantes da turma para contextualizar os conhecimentos químicos desenvolvidos em sala de aula com alguns aspectos do cotidiano dos estudantes. Entretanto, é importante salientar que o professor de ciências já trabalhou esse conteúdo com outros 


\section{تutดaดูão}

ISSN: 1984-6444 | http://dx.doi.org/10.5902/1984644434206 estudantes em anos anteriores, sendo a primeira vez que utilizou uma figura com esse tipo de linguagem para ilustrar e contextualizar o conhecimento químico trabalhado.

Nesse ano, muito provavelmente por causa do desafio de ensinar ciências para Pedro, o docente utilizou as duas representações da tabela periódica dos elementos, a ilustrada e a clássica, que é utilizada na ciência. Foi possível perceber que os demais estudantes também são beneficiados quando o professor tem um estudante com necessidades educacionais especiais ou com alguma deficiência. Afinal, essa situação exige um maior esforço para planejar as aulas com vistas a atender esses estudantes em suas particularidades e esse empenho acaba contemplando a todos em sala de aula.

Acreditamos que esse poderia ser um movimento realizado em todos os contextos escolares, mesmo que neles não se tenha algum estudante com necessidade educacional especial, já que a educação em ciências deve ser apresentada de uma forma contextualizada para atribuir sentido a tais conhecimentos. Os resultados da pesquisa de Miranda e Pinheiro (2016) mostram que, quando é aplicada uma proposta didática contextualizando o ensino de ciências no cotidiano dos estudantes com deficiência intelectual, eles conseguem construir conceitos científicos e matemáticos, motivados e com confiança em apresentar suas ideias, proporcionando um clima encorajador para a aprendizagem.

As figuras (b) e (c) foram coletadas do caderno de ciências dos estudantes, sendo uma atividade diferenciada que o professor realizou apenas com o Pedro. Com o trabalho envolvendo tais atividades, verificou-se mais uma possibilidade: desenvolver com o estudante atividades diferenciadas, com vistas a atender as suas singularidades. Enquanto o professor desenvolvia com a turma conhecimentos mais aprofundados a respeito da disposição e qualidades dos elementos químicos dispostos na tabela periódica, com o Pedro, o docente trabalhou de maneira mais detalhada os principais elementos dessa tabela. O professor trabalhou o conteúdo de modo mais descritivo, apresentando as qualidades daqueles elementos, a quantidade deles no universo e no corpo humano e onde mais é possível encontrá-los em nosso planeta. Os textos e as figuras que foram utilizadas foram obtidos na internet. 


\section{Autดaคูão}

ISSN: 1984-6444 | http://dx.doi.org/10.5902/1984644434206

Também foram trabalhadas as diferentes representações dos átomos e a sua organização em diversas moléculas de maneira lúdica. Os conhecimentos de ciências e matemática são importantes para possibilitar uma educação integral do estudante, assim, o professor deve trabalhá-los de uma forma dinâmica e prazerosa para o aluno, de modo a estimular a sua motivação em aprender (MIRANDA; PINHEIRO, 2016).

A atividade descrita anteriormente objetivava desenvolver aspectos gerais dos elementos químicos para iniciar o conteúdo de "constituição dos materiais por substâncias e misturas homogêneas e heterogêneas". Com o aluno Pedro, tal conteúdo foi trabalhado com mais detalhes também, enquanto que, com os demais estudantes da turma, o professor iniciou o conteúdo de forma sequencial, não necessitando de uma intervenção como a que foi realizada com o Pedro. Com tal aluno, não houve tanta preocupação com o tempo dispendido, tampouco com a quantidade de conteúdo desenvolvido.

Prieto (2006) defende que uma das competências esperadas dos docentes em sua prática é respeitar e considerar as diferenças individuais dos estudantes como um elemento essencial para a realização de um planejamento e estratégias avaliativas e de ensino que sejam condizentes e responsivas às peculiaridades de cada indivíduo. Não fazia sentido trabalhar com Pedro a quantidade de conteúdos propostos em detrimento da qualidade. Santos (2012) acrescenta que as ações didáticas para a educação do aluno com deficiência intelectual precisam ser individualizadas não somente no que tange às características de sua deficiência, mas, também, em relação à individualidade de cada pessoa (SANTOS, 2012).

Entretanto, um aspecto percebido a partir do trabalho com o Pedro e que precisa ser problematizado, inclusive com estudantes sem deficiência intelectual, é a quantidade exagerada de conhecimentos a serem trabalhados com os estudantes, 0 que acaba dificultando um melhor aprofundamento de aspectos que envolvem os fenômenos naturais. No currículo da referida escola, durante todo o $7^{\circ}$ ano é sugerido trabalhar muitos conhecimentos ligados à química, física, biologia e astronomia, sendo um desafio para professores que têm em suas salas de aula estudantes com deficiência intelectual e para aqueles que não têm. Com o Pedro, o professor conseguiu desenvolver os conteúdos de "constituição dos materiais por substâncias e 


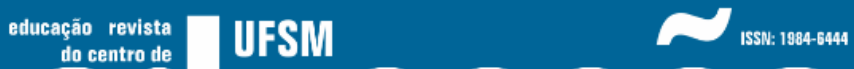 FutlaghaO}

ISSN: 1984-6444 | http://dx.doi.org/10.5902/1984644434206

misturas homogêneas e heterogêneas" de maneira lúdica, mas tardiamente, quando comparado com os demais estudantes da turma.

Ademais, havia momentos em que o docente desenvolvia também atividades inclusivas envolvendo toda a turma, trabalhando com os mesmos objetivos educacionais para todos os estudantes. O ensino para os estudantes com deficiência intelectual precisa atender às singularidades desses estudantes sem fugir daqueles princípios básicos da educação para os outros estudantes (SANTOS, 2012). Exemplo de outra atividade coletiva desenvolvida pensando em todos os alunos foi uma que o professor implementou com base nos pressupostos do ensino de ciências por investigação ( $\mathrm{EnCl})$. Assim, implementar atividades investigativas incluindo o estudante com deficiência intelectual foi outra possibilidade evidenciada.

A investigação é muito mais do que somente fazer perguntas, ela pode ser compreendida como uma série de processos que estão inter-relacionados, pelos quais os cientistas e os estudantes realizam questões a respeito do mundo natural e investigam os seus fenômenos (CRAWFORD, 2007). De acordo com a autora, o EnCl é uma abordagem utilizada pelos professores que consegue ensinar os conhecimentos científicos, além de abordar aspectos sobre a ciência e desenvolver habilidades científicas em sala de aula. Um aspecto que é essencial no ensino de ciências por investigação é o fato de ele possibilitar que os estudantes compreendam como trabalhar com dados e evidências em ciências e entender as observações realizadas à luz da lógica e do raciocínio científico (CRAWFORD, 2007).

A seguir, na figura 2, é possível visualizar alguns momentos da aplicação da atividade investigativa (AI) pelo docente a seus estudantes: 


\section{Autดaคูão}

ISSN: 1984-6444 | http://dx.doi.org/10.5902/1984644434206

A partir dessa pergunta de investigação, Pedro ficou com uma dúvida e formulou outra questão que não tinha sido planejada pelo professor: como é realizada a determinação do sexo biológico nos flamingos? O professor de ciências aproveitou o interesse de Pedro por essa temática e, em um segundo momento, realizou uma pesquisa com o aluno no laboratório de informática da escola a respeito das características que permitem diferenciar o flamingo macho da fêmea, com uma breve explicação a respeito da determinação sexual biológica.

Essa é uma possibilidade bem interessante, pois demonstra que o professor valoriza as questões que os estudantes fazem e, quando eles podem investigar problemas que são autênticos para eles, sua motivação para a aprendizagem pode ser muito maior. Santana (2016) aponta que situações como a descrita podem aprofundar os conhecimentos sobre uma determinada temática.

Nesse sentido, muito mais atividades práticas poderiam ser implementadas com Pedro a fim de permitir um maior protagonismo do estudante na construção de sua aprendizagem. Entretanto, acreditamos que as atuais condições para o desenvolvimento do trabalho docente, na maioria das escolas públicas brasileiras, acabam dificultando a implementação de atividades que requerem a participação mais ativa do aluno em seu processo de aprendizagem. Isso deve-se a uma realidade com uma grande quantidade de alunos na sala de aula, precárias condições físicas e estruturais nas escolas e ao pouco tempo remunerado disponibilizado para o planejamento de aulas mais inovadoras, que exigem muito tempo para o seu planejamento.

Além de atividades investigativas, o professor de ciências incluía também o máximo de figuras e estratégias lúdicas em suas atividades, pois percebeu que as condições de Pedro e seu nível de rendimento acadêmico exigiam isso. Atividades que eram consideradas simples para os demais estudantes eram difíceis para Pedro. O estudante estava regularmente matriculado no $7^{\circ}$ ano do ensino fundamental, entretanto, em uma avaliação das condições acadêmicas de Pedro, o professor percebeu que ele apresentava um rendimento acadêmico muito inferior aos seus colegas da mesma idade cronológica. 


\section{تutดaดูão}

ISSN: 1984-6444 | http://dx.doi.org/10.5902/1984644434206

Esse fato exigia que o professor utilizasse estratégias diferentes daquelas utilizadas com os demais estudantes e isso demandava do professor uma quantidade de tempo muito maior para o planejamento das ações pedagógicas naquela turma. Nesse sentido, o pouco tempo disponível para o planejamento foi um grande desafio para o docente. É necessário planejamento na educação de estudantes com deficiência intelectual, pois o processo de desenvolvimento das funções psíquicas complexas está mais comprometido em tais pessoas, o que os tornam ainda mais dependentes de ações sistematizadas, com objetivos bem definidos, com estratégias apropriadas e materiais adequados que possibilitem a construção conceitual, a aprendizagem dos conteúdos e o desenvolvimento de tais capacidades dos discentes (PADILHA, 2017).

A rede pública, na qual o docente trabalha, disponibiliza tempo para $\circ$ planejamento. Entretanto, consideramos esse tempo insuficiente para todas as demandas do docente, que incluem desde funções burocráticas, como lançamento de faltas e conteúdos no sistema online da rede, até atividades pedagógicas de planejamento. Muitas vezes, o professor realizava o planejamento e elaboração de tais atividades diferenciadas fora do seu horário remunerado de trabalho, em sua casa, para ser possível a realização de seu planejamento. Por isso, a experiência tida com Pedro corrobora a necessidade da disponibilidade de mais tempo remunerado para o planejamento das ações pedagógicas dos professores, sobretudo se ele possuir, matriculados em suas turmas, estudantes com diversas peculiaridades, que podem ser alguma deficiência ou outra singularidade que necessite de atendimento educacional especializado.

Outro desafio que o professor enfrentou em sua prática foi a dificuldade em desenvolver com Pedro todos os conteúdos propostos na matriz curricular para o seu ano escolar. Esse desafio foi mais percebido quando o professor desenvolveu com os estudantes conhecimentos físicos relacionados aos movimentos dos corpos. As figuras das atividades desenvolvidas com o estudante serão demonstradas a seguir: 


\section{A HEM

ISSN: 1984-6444 | http://dx.doi.org/10.5902/1984644434206

Figura 3 - Atividades desenvolvidas com Pedro envolvendo conhecimentos físicos.
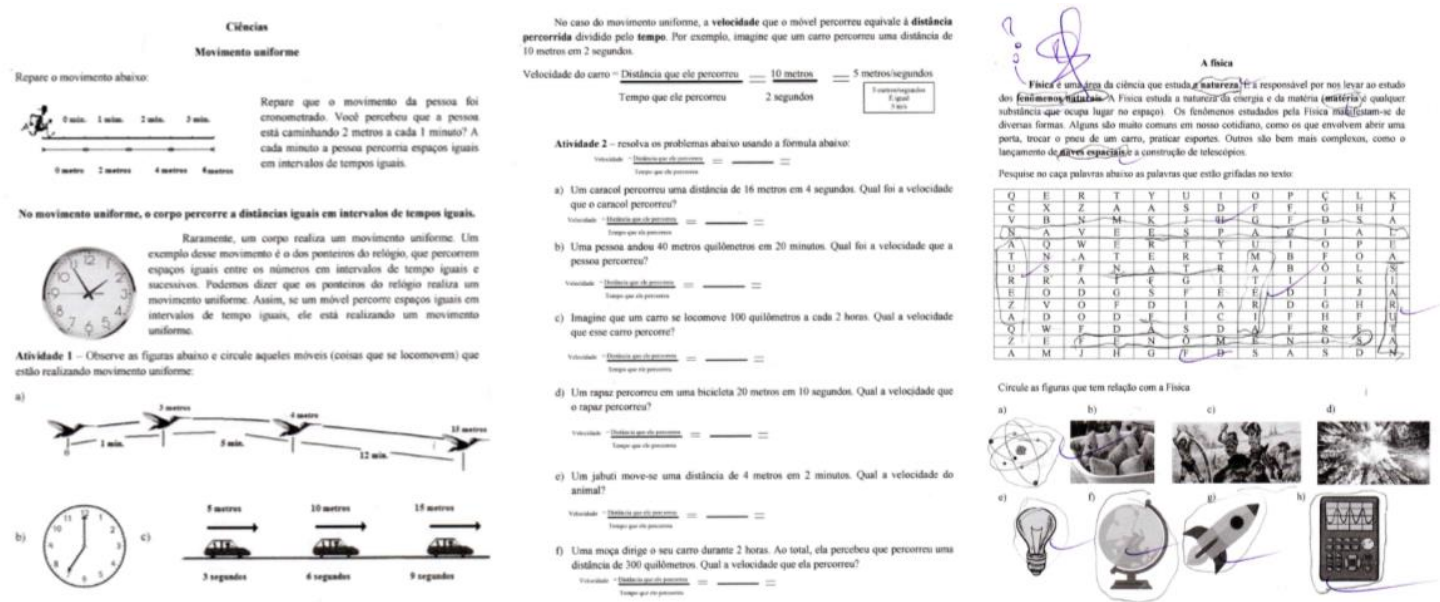

Fonte: Instrumentos de avaliação do professor de ciências (2018).

As atividades ilustradas apresentadas anteriormente foram montadas pelo professor para trabalhar aspectos do movimento uniforme dos corpos, conteúdo que também estava sendo desenvolvido com os demais estudantes da sala. Para desenvolver tal conteúdo, é preciso trabalhar com algumas habilidades matemáticas. Lang, Egelston-Dodd e Sachs (1983) salientam a importância da necessidade do desenvolvimento de habilidades matemáticas com estudantes que são o público-alvo da educação especial para o trabalho com alguns conhecimentos de ciências.

Entretanto, o professor teve muita dificuldade em trabalhar conhecimentos da física com o estudante com deficiência intelectual, pois Pedro não sabia realizar operações envolvendo a divisão de números. Com muitas dificuldades, ele apenas realizava operações de adição e subtração. Por conta dessa condição, e como a física não era o maior foco no currículo naquele ano escolar, o professor optou por trabalhar com Pedro de forma lúdica aspectos mais gerais dos conhecimentos da física, a fim de desenvolver com o estudante habilidades para diferenciar um fenômeno físico dos demais, não envolvendo conhecimentos matemáticos nas atividades.

Costa, Picharillo e Elias (2016) notaram que há poucas pesquisas acadêmicas a respeito da educação matemática para pessoas com deficiência intelectual e que ainda é preciso realizar um aprofundamento em investigações a respeito das operações aritméticas para estudantes com deficiência intelectual, sobretudo nas operações de multiplicação e divisão. 


\section{تutดaดูão}

ISSN: 1984-6444 | http://dx.doi.org/10.5902/1984644434206

Analisando a prática realizada, o professor percebeu que poderia ter procurado alguma formação para trabalhar com tais conhecimentos matemáticos com o seu estudante, considerando que possui formação em ciências biológicas. $O$ docente poderia também utilizar estratégias diferenciadas daquelas tradicionais para abordar aqueles conhecimentos aplicados aos fenômenos físicos. Contudo, no momento, ele optou por trabalhar com Pedro os conhecimentos físicos em seus aspectos mais gerais, sem se aprofundar nos movimentos dos corpos e envolver a matematização no ensino da física. Desse modo, ele deixou essa demanda para o professor de matemática. Uma possibilidade seria a realização de um trabalho interdisciplinar com o professor dessa disciplina, mas isso não foi possível naquele momento.

Outro desafio enfrentado durante o trabalho do professor com a série de Pedro foi a grande quantidade de alunos em sala de aula. Durante o desenvolvimento da prática havia 33 estudantes em sala, sendo que quase todos frequentavam as aulas, apenas um estudante tinha a frequência escolar comprometida por faltas. Essa quantidade de alunos em sala dificultou muito a realização de um melhor acompanhamento a todos os estudantes no que se refere à aprendizagem e aos objetivos educacionais apresentados no planejamento do professor.

Acreditamos que o processo de avaliação da aprendizagem precisa ser como um processo de investigação, realizado com o objetivo de acompanhar os alunos à luz dos objetivos do planejamento docente (ABIB, 2011). Entretanto, a quantidade de alunos tem um grande impacto nas possibilidades de realização de um processo investigativo na avaliação dos estudantes, pois o professor que atua nos anos finais do ensino fundamental e no ensino médio, geralmente, tem muitas turmas atribuídas a ele, aumentando ainda mais as suas demandas e dificultando um processo avaliativo mais aprofundado.

Ademais, uma possibilidade evidenciada a partir do trabalho com Pedro foi a realização de uma avaliação de maneira contínua e pontual, envolvendo aspectos conceituais, procedimentais e atitudinais. A figura 4 demonstra uma parte da avaliação bimestral de ciências que foi montada para utilizar com o estudante. 


\section{Eithrapẫ \\ 3}

ISSN: 1984-6444 | http://dx.doi.org/10.5902/1984644434206

Figura 4 - Parte da avaliação bimestral de Astronomia de Pedro, do $2^{\circ}$ bimestre.
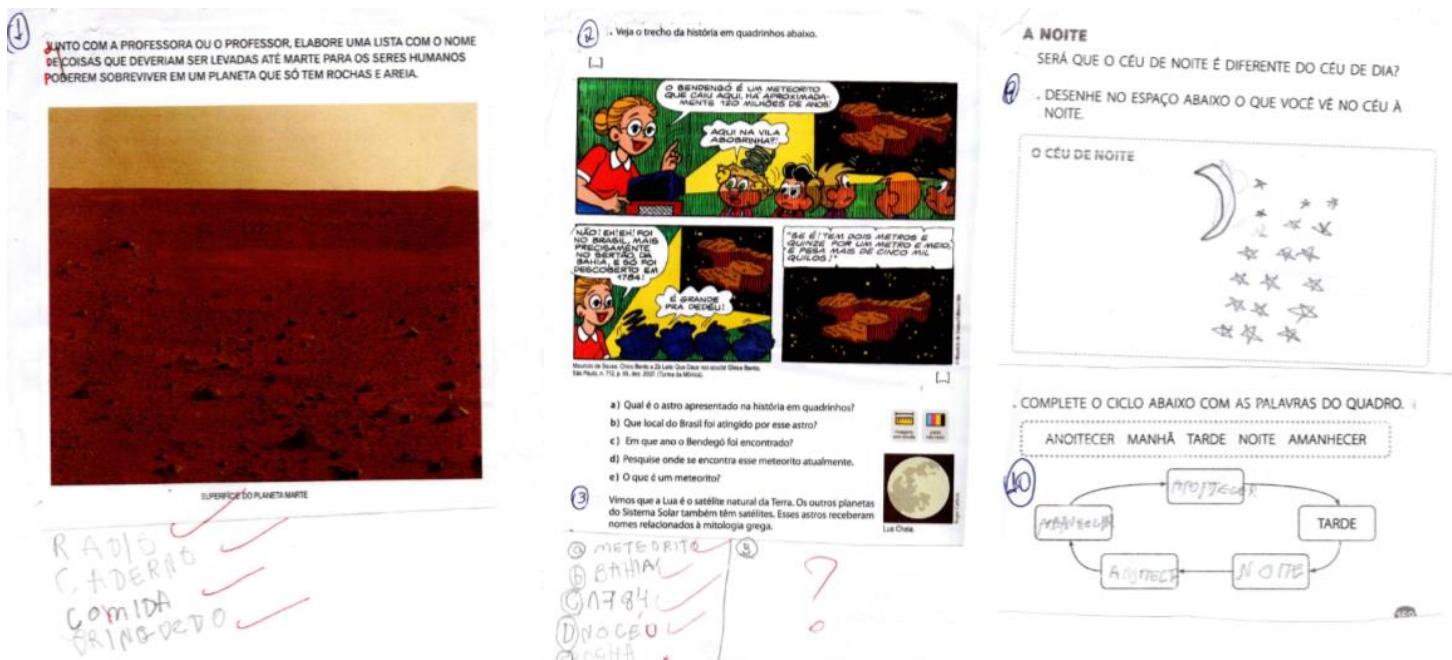

Fonte: Instrumentos de avaliação do professor de ciências (2018).

Essa avaliação bimestral (figura 4) foi diferente daquela aplicada aos demais estudantes da sala porque considerava a condição de Pedro, com questões conceituais que estavam apropriadas para o seu nível de desempenho acadêmico, contendo diversas ilustrações e em uma linguagem que o estudante conseguisse compreender para responder às questões. O conteúdo da avaliação foi o mesmo daquele aplicado à turma, com conhecimentos de astronomia, entretanto, a maneira de abordar a temática nas questões foi diferente, bem como a exigência conceitual das questões. Conforme apresentado na figura 4, Pedro conseguiu responder diversas questões e isso é um indício de que conseguiu compreender o conteúdo conceitual trabalhado em sala de aula.

Mesmo assim, havia algumas questões que Pedro tinha bastante dificuldade para responder devido ao seu percurso acadêmico. Entretanto, ao analisar as avaliações dos demais estudantes, o professor percebeu que muitos apresentavam dificuldades em relação ao conteúdo que os impediam de responder a todas as questões da avaliação, sendo que esse não era um desafio apenas de Pedro. Em Padilha (2018), é possível encontrar também dados que apresentam evidências de que os estudantes com deficiência intelectual podem compreender, ainda que parcialmente, conceitos relacionados às ciências. Costa et al. (2015) trazem dados que indicam que os estudantes com deficiência intelectual podem apresentar algumas 


\section{- Tusm Eutthab̧a}

ISSN: 1984-6444 | http://dx.doi.org/10.5902/1984644434206

dificuldades acadêmicas, principalmente no que se refere à compreensão dos conteúdos curriculares das disciplinas, devido a suas defasagens na aprendizagem.

É válido destacar que, na sala de Pedro, o professor pôde contar com uma estagiária $^{2}$ da escola que acompanhava o estudante e auxiliava o professor no processo de ensino. Dessa forma, o professor pôde contar com o auxílio de um estagiário para ajudar no trabalho com o estudante com deficiência intelectual. Este não substituiu o trabalho do professor, apenas dava um suporte para as atividades realizadas com Pedro, tendo em vista que ele precisava de um acompanhamento mais intensivo.

Muitos professores acreditam que, quando alunos com deficiência intelectual estão acompanhados de estagiários, o rendimento acadêmico é melhor, somando-se ao trabalho do docente e tornando essa atividade mais tranquila (COSTA, et al., 2015). Em sua pesquisa, Monteiro, Freitas Jorge (2018) apresentam evidências que corroboram a importância do acompanhamento mais próximo de uma pessoa, além do professor, para a formação de conceitos e para a melhor participação do estudante com deficiência intelectual. Ao final do segundo bimestre e início do terceiro, o contrato da estagiária, que era temporário, encerrou-se e o docente ficou cerca de dois meses sem a profissional, pois a escola estava aguardando o processo de contratação de uma nova profissional para acompanhar Pedro.

O período sem a estagiária foi muito desafiador, pois nem sempre o professor podia realizar um trabalho mais individualizado para o Pedro devido às demandas pedagógicas e disciplinares com os demais estudantes da sala. Ou seja, para ter um bom desempenho acadêmico nas atividades, Pedro precisava de acompanhamento individualizado. Nesse período, o professor procurava planejar atividades que 0 estudante conseguisse realizar com mais autonomia, com uma exigência menor e, em algumas aulas, quando era possível, realizava um maior acompanhamento com Pedro e aplicava ao estudante atividades mais complexas.

\footnotetext{
2 Este, geralmente é um estudante do curso de Licenciatura em Pedagogia que é contratado para realizar apoio ao professor regente que tem alunos considerados público-alvo da educação especial, mediante avaliação da necessidade do serviço. Tal apoio é instituído por meio do Decreto no 57.379 , de 13 de outubro de 2016 (SÃO PAULO, 2016).
} 


\section{F WEM ollubarao

ISSN: 1984-6444 | http://dx.doi.org/10.5902/1984644434206

É importante ressaltar que, mesmo com a presença de uma estagiária que acompanhava o estudante, era o professor quem planejava todas as atividades e realizava as orientações/intervenções para o ensino de ciências, trabalhando colaborativamente com ela. Os dados de Costa et al. (2015) mostram a importância do professor tutor como coadjuvante do processo de ensino do estudante com deficiência intelectual, trabalhando como mediador de todo o processo para que a inclusão desses estudantes de fato aconteça.

Por fim, nota-se que os dados apresentados na presente pesquisa dialogam e se relacionam com a produção científica recente sobre a aprendizagem e apropriação de conceitos por parte de alunos com deficiência intelectual (CORRÊA, 2016; MONTEIRO; FREITAS; JORGE, 2018; PADILHA, 2017; PADILHA, 2018; SILVA; SHIMAZAKI; MENEGASSI, 2017) na medida em que, assim como eles, destacam a importância da escola e da mediação do professor para a formação de conceitos destes estudantes (CORRÊA, 2016; MONTEIRO; FREITAS; JORGE, 2018; PADILHA, 2017). Essa questão evidencia a necessidade da utilização de várias estratégias (MONTEIRO; FREITAS; JORGE, 2018; SILVA; SHIMAZAKI; MENEGASSI, 2017), utilizando no ensino instrumentos presentes no cotidiano do aluno e contextualizando de acordo com a sua realidade (PADILHA, 2018; SILVA; SHIMAZAKI; MENEGASSI, 2017). É necessário, de igual modo, que se faça uso de diferentes gêneros da linguagem (MONTEIRO; FREITAS; JORGE, 2018), de forma lúdica (CORRÊA, 2016), aliado a ações organizadas, sistemáticas e com objetivos claros (PADILHA, 2017).

\section{Considerações finais}

A partir do trabalho realizado do primeiro ao terceiro bimestre na disciplina de ciências, foi possível perceber que o trabalho com estudantes que apresentam deficiência intelectual é bem desafiador, sendo possível explicitar possibilidades e algumas dificuldades durante o processo. Em suma, foi possível perceber que é viável realizar um trabalho satisfatório com tais estudantes, caso o professor inclua em suas práticas estratégias lúdicas, com diferentes linguagens, tarefas individuais e em grupo, além de atividades investigativas. 


\section{Autuarão}

ISSN: 1984-6444 | http://dx.doi.org/10.5902/1984644434206

É válido ressaltar que é importante que o professor de ciências considere as peculiaridades dos seus estudantes ao elaborar o planejamento de suas aulas, desenvolvendo propostas que envolvam preferencialmente o mesmo conteúdo para todos os estudantes, independentemente de suas singularidades e, sempre que possível, usando estratégias diferenciadas. $\mathrm{Na}$ maioria das vezes, tais estratégias acabam auxiliando o desenvolvimento do trabalho e colocando em prática aspectos do ensino de ciências para todos os estudantes, indistintamente.

Por meio das atividades desenvolvidas, foi possível notar o crescimento acadêmico do estudante com deficiência intelectual e o envolvimento do mesmo com as atividades propostas na disciplina de ciências, apesar das dificuldades que também fizeram parte do processo. Dessa forma, foram evidenciadas diversas possibilidades, tais como: trabalhar com recursos didáticos lúdicos, visando à contextualização do ensino com aspectos do cotidiano das pessoas, desenvolver com o estudante atividades diferenciadas, com vistas a atender as suas singularidades, implementar atividades investigativas, entre outras.

A partir do trabalho realizado com o aluno Pedro, também foram levantados diversos desafios, tais como: a dificuldade em adaptar todos os conteúdos científicos escolares; pouco tempo remunerado para o planejamento das atividades e a grande quantidade de estudantes na sala de aula, o que dificulta a realização de um melhor acompanhamento da aprendizagem. É possível perceber que os desafios citados não são específicos para estudantes com deficiência intelectual, sendo a dificuldade em realizar uma boa transposição didática, escassez de tempo para o planejamento e quantidade de alunos em sala de aula desafios que afligem também a educação, de maneira geral. Entretanto, quando há um estudante com necessidades educacionais especiais em sala de aula, como aqueles com deficiência intelectual, tais desafios são intensificados pelas peculiaridades de tais alunos.

Por derradeiro, é importante salientar a necessidade de que outras pesquisas que envolvam o ensino de ciências sejam realizadas, considerando o público com deficiência intelectual. As discussões iniciadas neste trabalho trazem contribuições para o campo da educação em ciências, na medida em que permitem que a comunidade científica e os professores compreendam melhor as especificidades, 


\section{Uism \\ ISSN: 1984-6444 \\ Entuahá}

ISSN: 1984-6444 | http://dx.doi.org/10.5902/1984644434206

possibilidades e desafios que envolvem ensinar ciências para estudantes com necessidades educacionais especiais.

\section{Referências}

ABIB, Maria Lucia Vital dos Santos. Avaliação e melhoria da aprendizagem em Física. In: CARVALHO, Anna Maria Pessoa de. (Org.). Ensino de Física - Coleção idéias em ação. São Paulo: Cengage, 2011, p. 141-158.

American Association on Intellectual and Developmental Disabilities (AAIDD). Definition of Intellectual Disability. Disponívelem: http://aaidd.org/intellectualdisability/definition. Acesso em: 12 set. 2018.

BOGDAN, Robert. C.; BIKLEN, Sari. Investigação qualitativa em educação: uma introdução à teoria e aos métodos. Portugal: Porto Editora, 1994.

BUENO, José Geraldo S. As políticas de inclusão escolar: uma prerrogativa da Educação Especial? In: BUENO, J.G.; MENDES, G; SANTOS, R. (orgs.). Deficiência e escolarização: novas perspectivas de análise. Araraquara: Junqueira \& Marin: Brasília: CAPES, 2008.

BRASIL. Ministério da Educação. Política Nacional de Educação Especial na Perspectiva da Educação Inclusiva. Brasília, DF, 2008.

CORREAA, Roberta Pires. A formação de conceitos em alunos com deficiência intelecutal: aspectos do processo de ensino e aprendizagem. 2016. $147 \mathrm{f}$. Dissertação (Mestrado Profissional em Diversidade e Inclusão) - Mestrado Profissional em Diversidade e Inclusão do Departamento de Biologia do Instituto de Biologia da Universidade Federal Fluminense, Rio de Janeiro, 2016.

COSTA, Ailton Barcelos da; PICHARILLO, Alessandra Daniele Messali; ELIAS, Nassim Chamel. Habilidades Matemáticas em Pessoas com Deficiência Intelectual: um Olhar Sobre os Estudos Experimentais. Revista Brasileira de Educação Especial, Marília, v. 22, n. 1, p. 145-160, 2016. Disponível em: www.scielo.br/pdf/rbee/v22n1/1413-6538-rbee-22-01-0145.pdf. Acesso em: 05 ago. 2018.

COSTA, Analia Maria de Fátima; LIMA, Siumara Aparecida de; STADLER, Rita de Cássia da Luz; CARLETTO, Marcia Regina. A importância da tutoria no ensino de Ciências Naturais com alunos especiais. Investigações em Ensino de Ciências, Porto Alegre, v. 20, n. 1, p. 127-141, 2015. Disponível em: https://www.if.ufrgs.br/cref/ojs/index.php/ienci/article/view/62/39. Acessoem: 05 ago. 2018. 


\section{U usm AUthabुO}

ISSN: 1984-6444 | http://dx.doi.org/10.5902/1984644434206

CRAWFORD, Barbara. Learning to Teach Science as Inquiry in the Rough and Tumble of Practice.Journal of Research in Science Teaching, v. 44, n. 4, p. 613-642, 2007. Disponívelem: https://onlinelibrary.wiley.com/doi/abs/10.1002/tea.20157. Acesso em: 05 ago. 2018.

DUARTE, Clarice Seixas. A educação como um direito fundamental de natureza social. Educação \& Sociedade, Campinas, n. 28, n. 100, p. 691-713, 2007. Disponível em: www.scielo.br/pdf/es/v28n100/a0428100.pdf. Acesso em: 05 ago. 2018.

GADOTTI, Moacir. Qualidade na educação: uma nova abordagem. 1. ed. São Paulo: Editora e Livraria Instituto Paulo Freire, 2010.

LABURU, Carlos Eduardo; ARRUDA, Sérgio de Mello; NARDI, Roberto. Pluralismo metodológico no ensino de ciências. Ciência \& Educação, Bauru, v. 9, n. 2, p. 247260, 2003. Disponível em: www.scielo.br/pdf/ciedu/v9n2/07.pdf. Acesso em: 05 ago. 2018.

LANG, Harry; EGELSTON-DODD, Judy; SACHS, Marvin.Science Education for Hearing-Impaired Students in the Eighties: Priorities and Projections. American Annals of the Deaf, v. 128, n. 6, p. 801-808, 1983. Disponível em: muse.jhu.edu/article/385986. Acesso em: 05 ago. 2018.

MANTOAN, Maria Tereza Eglér. Igualdade e diferenças na escola: como andar no fio da navalha. In: ARANTES, VALERIA AMORIM. (Org.). Inclusão escolar: pontos e contrapontos. São Paulo: Summus, 2006. p. 15-30.

MIRANDA, Amanda Drzewinskide; PINHEIRO, Nilcéia Aparecida Maciel. O ensino da Matemática ao deficiente intelectual: projetos de trabalho em uma perspectiva contextualizada e interdisciplinar. Revista Educação Especial, Santa Maria, v. 29, n. 56, p. 695-708, 2016. Disponível em: https://periodicos.ufsm.br/educacaoespecial/article/view/17805/pdf. Acesso em: 05 ago. 2018.

MONTEIRO, Maria Inês Bacellar; FREITAS, Ana Paula d; JORGE, Luísa Miranda. Possibilidades e desafios da escola: formação de conceitos científicos de alunos com deficiência intelectual. Cadernos de Pesquisa, São Luís, v. 25, n. 1, p. 79-94, 2018. Disponível

em: http://www.periodicoseletronicos.ufma.br/index.php/cadernosdepesquisa/article/view/ 8871/5381. Acesso em: 12 set. 2018.

MORAES, Roque; GALIAZZI, Maria do Carmo. Análise Textual Discursiva. 3. ed. Ver. E ampl. - ljuí: Ed. Unijuí, 2016.

OLIVEIRA, Romualdo Portela de; ARAUJO, Gilda Cardoso de. Qualidade do ensino: uma nova dimensão da luta pelo direito à educação. Revista Brasileira de Educação, Rio de Janeiro, n. 28, p. 5-23, 2005. Disponível em: www.scielo.br/pdf/rbedu/n28/a02n28.pdf. Acesso em: 05 ago. 2018. 


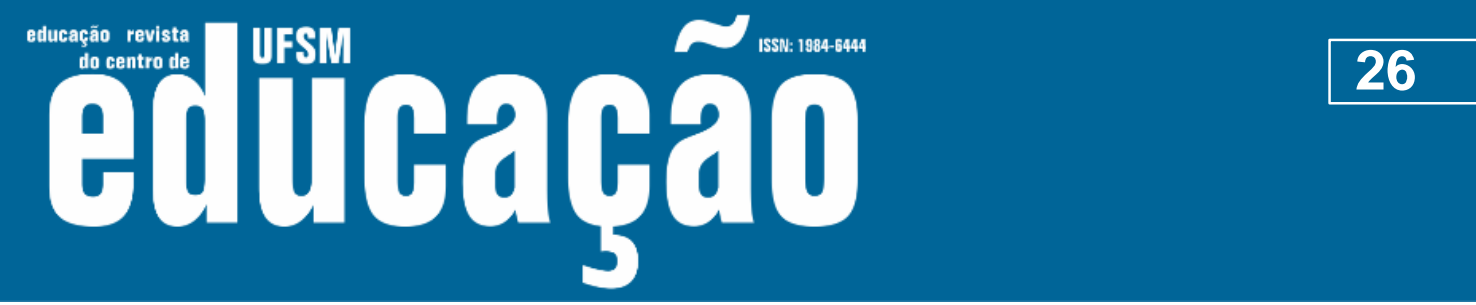

ISSN: 1984-6444 | http://dx.doi.org/10.5902/1984644434206

PADILHA, Anna Maria Lunardi. Desenvolvimento Psíquico e Elaboração Conceitual por Alunos com Deficiência Intelectual na Educação Escolar. Revista Brasileira de Educação Especial, Marília, v. 23, n. 1, p.9-20, 2017.

PADILHA, Juliana Caixeta. A mediação docente dos conceitos básicos da genética para alunos com deficiência intelectual. 2018. 215 f. Dissertação (Mestrado profissional em Ensino na Educação Básica) - Programa de PósGraduação em Ensino na Educação Básica do Centro de Ensino e Pesquisa Aplicada à Educação da Universidade Federal de Goiás, Goiás, 2018.

PRIETO, Rosângela Gavioli. Atendimento escolar de alunos com necessidades educacionais especiais: um olhar sobre as políticas públicas de educação no Brasil. In: ARANTES, VALERIA AMORIM. (Org.). Inclusão escolar: pontos e contrapontos. São Paulo: Summus, 2006. p. 15-30.

RODRIGUES, DAVID. Dez ideias (mal) feitas sobre a Educação Inclusiva. In: RODRIGUES, David (org.). Inclusão e Educação: doze olhares sobre a Educação Inclusiva. São Paulo: Summus Editorial, 2006.

SANTANA, Ronaldo Santos. A realidade do ensino por investigação na práxis dos professores dos anos iniciais do ensino fundamental: possibilidades e desafios. 2016. 162 f. Dissertação (mestrado) - Universidade Federal do ABC, Programa De Pós-Graduação em Ensino, História, Filosofia das Ciências e Matemática, 2016.

SANTOS, Daísy Cléia Oliveira dos. Potenciais dificuldades e facilidades na educação de alunos com deficiência intelectual. Educação e Pesquisa, São Paulo, v. 38, n. 4, p. 935-948, 2012. Disponível em: www.scielo.br/pdf/ep/v38n4/10.pdf. Acesso em: 05 ago. 2018.

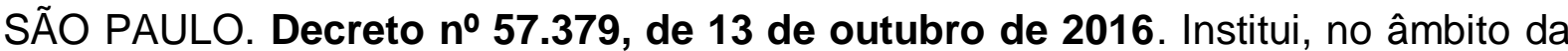
Secretaria Municipal de Educação, a Política Paulistana de Educação Especial, na Perspectiva da Educação Inclusiva. Disponível em: http://legislacao.prefeitura.sp.gov.br/leis/decreto-57379-de-13-de-outubro-de-2016. Acesso em: 15 set. 2018.

SILVA, Sani de Carvalho Rutz da; SHIMAZAKI, Elsa Midori; MENEGASSI, Renilson José. A formação de conceitos em ciências naturais por alunos com deficiência intelectual. Enseñanza de las Ciencias, n. Extra, p. 1203-1207, 2017. Disponível em: https://ddd.uab.cat/pub/edlc/edlc_a2017nEXTRA/26_-

A_formacao_de_conceitos_em_Ciencias_Naturais_por_alunos_com_deficiencia_in telectual.pdf. Acesso em: 12 set. 2018.

VILELA-RIBEIRO, Eveline Borges; BENITE, Anna Maria Canavarro. Alfabetização científica e educação inclusiva no discurso de professores formadores de professores de ciências. Ciência \& Educação, Bauru, v. 19, n. 3, p. 781-794, 2013. Disponível em: www.scielo.br/pdf/ciedu/v19n3/16.pdf. Acesso em: 05 ago. 2018. 


\section{N

\section{Agradecimentos}

ISSN: 1984-6444 | http://dx.doi.org/10.5902/1984644434206

Os autores deste trabalho agradecem ao apoio do Conselho Nacional de Desenvolvimento Científico e Tecnológico (CNPq). Agradecemos aos professores Michael de Araújo Teodozio, Aline Lopes Rodrigues e Enios Carlos Duarte pela elaboração da atividade investigativa utilizada. Por fim, somos gratos aos professores e à equipe gestora da escola de implementação pelo forte apoio às atividades de ciências realizadas.

\section{Correspondência}

Ronaldo Santos Santana - Doutorando na Universidade de São Paulo, São Paulo, São Paulo, Brasil.

Cássia Geciauskas Sofiato - Professora doutora da Universidade de São Paulo, São Paulo, São Paulo, Brasil.

Universidade de São Paulo, Programa de Pós-graduação em Educação. Cidade Universitária, Butantã. CEP: 05508-900.São Paulo, São Paulo, Brasil.

E-mail: prof.ronaldosantana@gmail.com - cassiasofiato@usp.br

Recebido em 28 de setembro de 2018

Aprovado em 27 de novembro de 2018

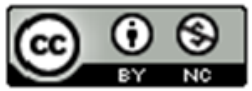

The is work is licensed under a Creative Commons Attribution-NonCommercial 4.0 International (CC BY-NC 4.0) 